\title{
Epidural lidocaine with sufentanil and epineph- rine for abdominal hysterectomy under general anaesthesia: respiratory depression and postoperative analgesia
}

\begin{abstract}
The purpose of this investigation was to compare the analgesic actions and side-effects of a $50 \mu \mathrm{g}$ epidural bolus of sufentanil and $50 \mu \mathrm{g}$ epinephrine, with a control group receiving saline and epinephrine. The method employed was a prospective, randomised, double-blind trial involving 40 ASA I or II patients for total abdominal hysterectomy. All received $1.5 \%$ lidocaine with 1/200,000 epinephrine epidurally before operation, until a block to $T_{4}$ was established. Patients were anaesthetised, their tracheas were intubated, and they were allowed to breathe spontaneously before administration of the test drug. Results showed that sufentanil prolonged the duration of local anaesthesia (198 \pm 35 min vs $174 \pm 29$ min; $P<0.05)$, and of analgesia $(288 \pm 85 \mathrm{~min}$ vs $188 \pm 42 \mathrm{~min} ; P<0.01)$. There was an increase in somnolence in the sufentanil group $(9 / 20 \mathrm{vs} 2 / 20$; $P<0.05)$. Glycopyrollate was given to $11 / 20$ patients in the sufentanil group vs $1 / 20$ in the control group $(P<0.01)$ following bradycardia and hypotension. Clinical respiratory depression occurred in the sufentanil group; $5 / 20$ patients required controlled ventilation following apnoea $>20 \mathrm{sec}$. It is concluded that epidural sufentanil causes considerable cardiorespiratory
\end{abstract}

\section{Key words}

ANAESTHETIC TECHNIQUES: regional, epidural;

ANALGESICS: sufentanil;

VENTILATION: apnoea, failure.

From the Department of Anaesthesia, Groote Schuur Hospital and University of Cape Town, Observatory, 7925, South Africa.

Address correspondence to: Dr. R.A. Dyer, Department of Anaesthesia, Groote Schuur Hospital and University of Cape Town, Observatory, 7925, South Africa.

Accepted for publication 4 th November, 1991.
Robert A. Dyer FFA(SA), Kevin Camden-Smith FFA(SA), Michael F.M. James PhD depression in the setting of general anaesthesia, and should be used with caution in the spontaneously breathing, anaesthetised patient.

Le but de cette investigation était de comparer l'analgésie et les effets secondaires obtenus suite à un bolus épidural de $50 \mu \mathrm{g}$ de sufentanil et de $50 \mu \mathrm{g}$ d'épinéphrine, à un groupe contrôle recevant du salin et de l'épinéphrine. Cette étude prospective, au hasard et à double insu, impliquait 40 patientes ASA 1 ou 2, devant subir une hystérectomie abdominale totale. Avant la chirugie, un bloc épidural était établi au niveau $T_{4}$ à l'aide de lidocaïne 1,5\% et d'épinéphrine, 1/200 000. Par la suite, les patientes étaient anesthésiées, une intubation endotrachéale réalisée, et le médicament à évaluer administré après la reprise de la ventilation spontanée. Les résultats ont démontré que le sufentanil prolongeait la durée de l'anesthésie locale $(198 \pm 35$ min vs $174 \pm 29$ min; $P<0,05)$, et de l'analgésie $(288 \pm 85 \mathrm{~min}$ vs $188 \pm 42 \min ; P<0,01$ ). Il y avait une augmentation de la sommolence dans le groupe sufentanil $(9 / 20$ vs $2 / 20 ; P<0,05)$. Le glycopyrrolate a été nécessaire chez 11 patients sur 20 dans la groupe sufentanil et chez I pateinte sur 20 dans le groupe contrôle $(P<0,01)$ suite à une bradycardie et à une hypotension. Une dépression respiratoire clinique est survenue dans le groupe sufentanil : 5 patients sur 20 ont eu besoin de ventilation contôlée suite à une apnée de plus de 20 secondes. En conclusion, le sufentanil épidural provoque une dépression cardiorespiratoire considérable dans le contexte d'une anes. thésie générale, et devrait être utilisé avec précaution chez le patient anesthésié et en ventilation spontanée.

Epidural anaesthesia in combination with a light general anaesthetic is a well-accepted technique for gynaecological procedures. The combination of epidural opioids with local 
anaesthetics is a frequently employed method of postoperative analgesia. ${ }^{1}$ Hydrophilic opiates such as morphine may be associated with late respiratory depression when administered epidurally, and their use requires the presence of adequate monitoring for $24 \mathrm{hr}$ in a high-dependency unit. ${ }^{2,3}$ Sufentanil, a potent lipid soluble opiate with high $\mu$ receptor affinity, has been employed in several recent studies on postoperative analgesia following abdominal surgery. 1,4,5 Analgesia is rapid in onset and of two to six hours duration following 50 to $75 \mu \mathrm{g}$ epidural sufentanil in abdominal surgical cases. ${ }^{1,4,6}$ The addition of epinephrine may prolong the effect. ${ }^{7}$ Though there have been no reports of delayed respiratory depression following epidural sufentanil, evidence of early respiratory depression remains controversial. ${ }^{3}$

No previous studies have examined the interaction of epidural opiates and general anaesthesia on respiratory function. As many patients may receive their first dose of epidural opiate either during anaesthesia or in the early recovery phase, such an interaction may be clinically important.

This randomized, prospective, double-blind study was designed to assess the effect of epidural sufentanil on early respiratory depression when administered to intubated spontaneously breathing patients under general anaesthesia in combination with epidural lidocaine and epinephrine, and to study the duration of postoperative analgesia.

\section{Methods}

Forty ASA I or II patients for elective total abdominal hysterectomy were studied, using a combination of epidural and light general anaesthesia. The study was approved by the University of Cape Town Ethics Committee and informed written consent was obtained. Preoperatively, random allocation of patients into two groups, using tables of random numbers, was made in the pharmacy where sterile, preservative-free opiate solutions were prepared. There were 20 patients in each group. All patients received a premedication of $20 \mathrm{mg}$ temazepam orally, two hours preoperatively. An intravenous infusion was established prior to epidural insertion, and $15 \mathrm{ml} \cdot \mathrm{kg}^{-1}$ of a balanced electrolyte solution were administered. Immediately preoperatively, an epidural catheter was inserted by one of the investigators at the $\mathrm{L}_{2,3}$ level, using the loss of resistance technique. All patients received sequential doses of lidocaine $1.5 \%$ with epinephrine $1 / 200000$ until sensory blockade to the $T_{4}$ level was established. Sensory block was assessed by cold sensitivity and motor block according to the Bromage criteria. ${ }^{8}$ Anaesthesia was induced with etomidate (given to loss of eyelash reflex) and tracheal intubation was facilitated with succinylcholine $1 \mathrm{mg} \cdot \mathrm{kg}^{-1}$ following topical spray with lidocaine $4 \%$. Maintenance of anaesthesia was with $65 \%$ nitrous oxide in oxygen, and enflurane $1.5-2 \%$. After ten minutes of spontaneous breathing following recovery from succinylcholine, patients in Group 1 received $50 \mu \mathrm{g}$ sufentanil in $10 \mathrm{ml}$ normal saline with $1 / 200000$ epinephrine and Group 2 patients (control) were given $10 \mathrm{ml}$ normal saline with $1 / 200000$ epinephrine epidurally. All anaesthetics and observations were performed by the authors.

Patient monitoring included continuous ECG, noninvasive blood pressure measurement at three-minute intervals using a Dinamap (Critikon), end-tidal $\mathrm{PCO}_{2}$ measurement using a pre-calibrated capnograph, tidal volume recordings on a Wright respirometer, haemoglobin saturation by pulse oximetry, and serial arterial blood gases via a 22-gauge catheter in the radial artery of the nondominant hand. Baseline recordings prior to administration of the epidural opiate included heart rate, blood pressure, tidal volume, end-tidal $\mathrm{PCO}_{2}$ and arterial blood gases. All measurements except blood gases were performed at five minutes after the administration of sufentanil. Subsequently recordings were made of all indices every ten minutes for the first hour, then every $30 \mathrm{~min}$ until enflurane was discontinued. Glycopyrollate $0.4 \mathrm{mg}$ was administered intravenously if heart rate decreased to $<70 \cdot \mathrm{min}^{-1}$ in the presence of a systolic blood pressure of $<80 \mathrm{mmHg}$ after more than $30 \mathrm{ml} \cdot \mathrm{kg}^{-1}$ of intravenous crystalloid. Persistent hypotension was treated with ephedrine in $5 \mathrm{mg}$ intravenous increments. Enflurane was discontinued 20 min before the anticipated end of surgery, and intraoperative data analysis was terminated either at this point or if patients had previously become apnoeic and required ventilation.

Postoperatively, patients were closely monitored in a high-care recovery area. The ECG, haemoglobin saturation and respiratory rate were recorded and arterial blood gases measured every $30 \mathrm{~min}$.

Recovery from the effect of epidural lidocaine was assessed by cold sensitivity (the endpoint was recession of the block to below the segmental level of the abdominal incision) and Bromage criteria for motor power. At 30-min intervals, pain was assessed by the operator blinded to the intraoperative respiratory measurements. A numerical pain score with anchor words was used (worst pain imaginable 10 , to no pain 0 ). When the pain score was increased to $>5$, morphine $0.05 \mathrm{mg} \cdot \mathrm{kg}^{-1}$ iv and $0.1 \mathrm{mg} \cdot \mathrm{kg}^{-1}$ im were administered and the patient was returned to the general ward $30 \mathrm{~min}$ after receiving morphine, when the arterial line and epidural catheter had been removed. Total analgesic time was recorded from time of administration of epidural lidocaine to time of administration of postoperative morphine.

Side-effects were recorded objectively by the investigator, or if volunteered, by the patient; no direct questioning 


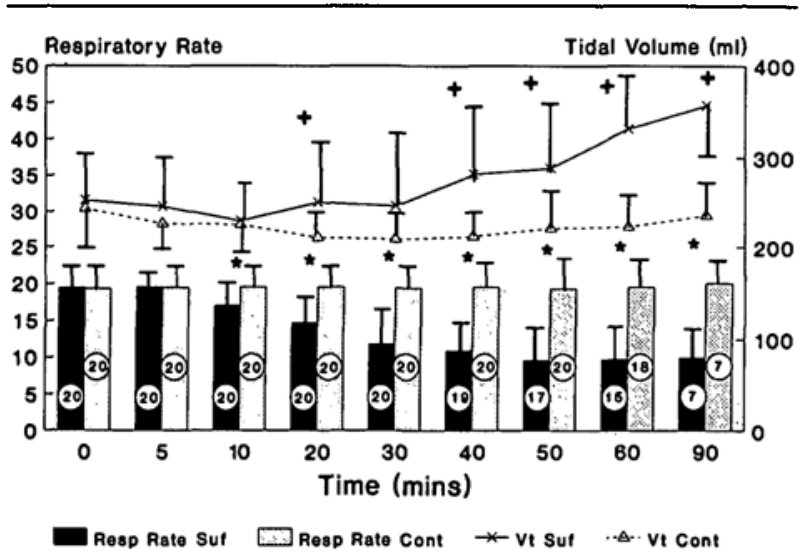

FIGURE 1 Comparison of tidal volumes and respiratory rates in spontaneously breathing patients between the two groups with time, after epidural sufentanil. Resp Rate Suf - respiratory rates in the sufentanil group. Resp Rate Cont - respiratory rates in controls. VT Suf - tidal volume in the sufentanil group. VT Cont - tidal volume in controls. $* P<0.05$ for between-group differences in respiratory rates. $\dagger P<0.05$ for between-group differences in tidal volumes. Circled numbers indicate numbers of patients remaining in analysis after exclusion of apnoeic patients.

TABLE I Demographic data

\begin{tabular}{lcccc}
\hline & Group 1 & (SD) & Group 2 & (SD) \\
\hline$n$ & 20 & & 20 & \\
Age (yr) & 41.4 & $(4.8)$ & 40.6 & $(6.1)$ \\
Height (cm) & 163 & $(6)$ & 159 & $(7)$ \\
Weight (kg) & $70^{*}$ & $(10)$ & 60 & $(10)$ \\
Duration of surgery (min) & 111 & $(36)$ & 102 & $(39)$ \\
Total lidocaine (ml) & 19 & $(3)$ & 19 & $(3)$ \\
\hline
\end{tabular}

$* P<0.05$.

was used. Pruritus was recorded on a scale 0 nil, 1 mild, 2 moderate and 3 severe, and emesis as 0 nil, 1 nausea and 2 vomiting. Somnolence (the worst score during the $30-$ min period) was recorded as 0 awake, 1 normal sleep, 2 drowsy and 3 unrousable. The total morphine requirement for the subsequent $24 \mathrm{hr}$ was also noted.

Between group comparisons were performed using Student's t test for parametric data or the Mann-Whitney $\mathrm{U}$ test for nonparametric data. Analysis of variance for repeated measures was used for the determination of differences between successive data points within each group. All statistical analyses were performed using a PC-based statistical package (Statgraphics).

\section{Results}

Results for numerical data are presented as means \pm SD.

The demographic data of the two groups were comparable (Table I) except for patient weights.

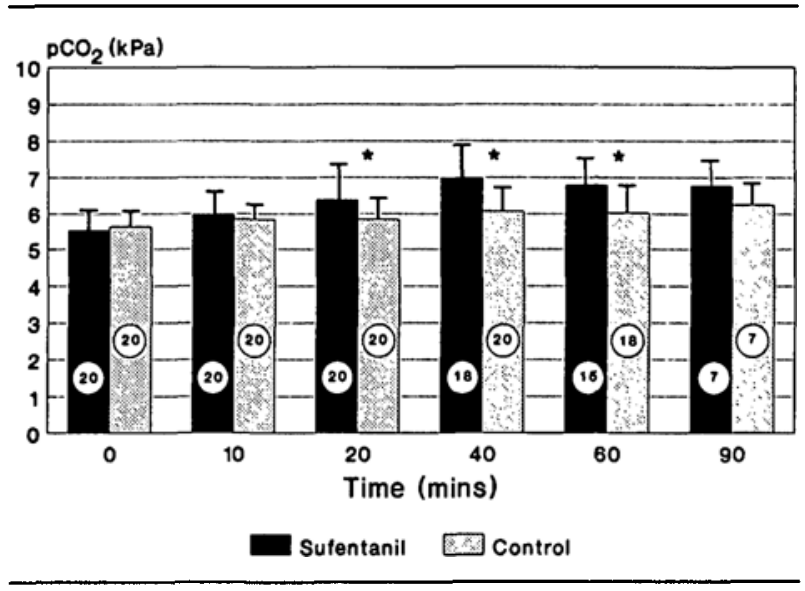

FIGURE 2 Comparison of $\mathrm{PaCO}_{2}$ values between the two groups with time, after epidural sufentanil. ${ }^{*} P<0.05$ for between ground differences.

\section{Analgesia}

Sufentanil prolonged the duration of the local anaesthesia (Group 1: $198 \pm 35 \mathrm{~min}$, Group 2: $174 \pm 29 \mathrm{~min} ; P<$ $0.05)$. Total analgesic time was also prolonged in Group 1 ( $288 \pm 85 \mathrm{~min}$ vs $188 \pm 42 \mathrm{~min} ; P<0.01$ ). The time from cessation of action of local anaesthetic to administration of morphine was again significantly less in Group 2 than Group 1 (14 $\mathrm{min}$ vs $90 \mathrm{~min}$ ). There was no difference in morphine requirement for the subsequent $24 \mathrm{hr}$ (3.15 \pm 0.48 vs $3.30 \pm 0.64$ doses).

\section{Ventilatory disturbances}

There were no differences between baseline breath rates, $\mathrm{PaCO}_{2}$ values or tidal volumes in the two groups. Figure 1 shows the trend towards increasing tidal volume and decrease in breath rate in Group 1 patients breathing spontaneously after the epidural bolus. The concomitant increase in $\mathrm{PaCO}_{2}$ in Group 1 patients is shown in Figure 2.

Five patients in Group 1 became apnoeic for more than $20 \mathrm{sec}$ and their lungs were ventilated until the end of the procedure. This occurred at $30,40,50,50$ and $60 \mathrm{~min}$, respectively, after the epidural bolus. There was also an increase in $\mathrm{PETCO}_{2}$ from $30-90 \mathrm{~min}$ in the sufentanil group. Postoperatively, no patient had a respiratory rate $<10$ per min, and only four patients in Group 1 had transiently elevated $\mathrm{PaCO}_{2}$ values, between 6 and $7 \mathrm{kPa}$, and for which no therapy was required.

\section{Cardiovascular disturbances}

Preoperative systolic and diastolic blood pressures, measured after establishment of sensorineural blockade to the $T_{4}$ level, were not different between Group 1 and 2 . Furthermore, intravenous fluid requirements were also not different ( 2825 vs $2475 \mathrm{ml}$ respectively). More patients in 
TABLE II Haemodynamic changes following epidural sufentanil

\begin{tabular}{lcccccccc}
\hline $\begin{array}{l}\text { Time post- } \\
\text { sufentanil (min) }\end{array}$ & 0 & 10 & 20 & 30 & 40 & 50 & 60 & 90 \\
\hline Heart rate & & $*$ & $*$ & $*$ & $*$ & $*$ & & \\
Group 1 & 81.2 & 77.5 & 78.6 & 73.3 & $70.6 \dagger$ & 72.9 & 77.1 & 81.6 \\
$\quad$ (SD) & $(13.0)$ & $(10.2)$ & $(9.7)$ & $(8.8)$ & $(9.2)$ & $(9.5)$ & $(10.6)$ & $(7.5)$ \\
Group 2 & 79.6 & 84.6 & 86.8 & 84.1 & 83.8 & 82.4 & 81.7 & 83.29 \\
$\quad$ (SD) & $(10.8)$ & $(8.1)$ & $(8.3)$ & $(7.4)$ & $(8.7)$ & $(9.3)$ & $(7.9)$ & $(6.1)$ \\
& & & & & & & & \\
MAP & & & & & $*$ & & & $*$ \\
Group 1 & 75.1 & 72.3 & 68.0 & 65.8 & $63.7 \dagger$ & 68.9 & $62.3 \dagger$ & 66.1 \\
$\quad$ (SD) & $(9.8)$ & $(9.1)$ & $(11.9)$ & $(9.0)$ & $(8.3)$ & $(19.1)$ & $(7.9)$ & $(4.8)$ \\
Group 2 & 71.8 & 79.5 & 73.9 & 72.9 & 70.8 & 71.6 & 71.9 & 79.7 \\
$\quad$ (SD) & $(12.7)$ & $(18.9)$ & $(17.5)$ & $(14.1)$ & $(9.9)$ & $(11.8)$ & $(12.5)$ & $(11.3)$ \\
\hline
\end{tabular}

${ }^{*} P<0.05$ for between-group differences.

$\dagger P<0.05$ for within-group differences from Time 0 (administration of epidural sufentanil).

TABLE III Side-Effects*

\begin{tabular}{|c|c|c|c|c|c|c|c|c|}
\hline \multirow[b]{2}{*}{ Score } & \multicolumn{4}{|c|}{ Lidocaine } & \multicolumn{4}{|c|}{ Lidocaine and sufentanil } \\
\hline & 0 & 1 & 2 & 3 & 0 & 1 & 2 & 3 \\
\hline Somnolence & 18 & 2 & 0 & 0 & 11 & 2 & $7 \dagger$ & 0 \\
\hline Pruritus & 20 & 0 & 0 & 0 & 17 & 3 & 0 & 0 \\
\hline Emesis & 20 & 0 & 0 & - & 15 & 1 & 4 & - \\
\hline
\end{tabular}

*Number of patients out of 20 in each group exhibiting the score indicated (see text).

$\dagger P<0.05$.

Group $1(11 / 20)$ required glycopyrollate than in Group 2 $(1 / 20, P<0.01)$. Despite the use of glycopyrollate, heart rates remained lower in Group 1 for the first 50 min after the administration of sufentanil. Mean arterial pressures were also lower in Group 1 at 40,60 and $90 \mathrm{~min}$ (see Table II), with one patient in this group requiring ephedrine for persistent hypotension.

\section{Side-effects}

The incidence of side-effects is shown in Table III. Patients in Group 1 had a greater incidence of somnolence, but none was unrousable postoperatively. Pruritus was seen in three patients in Group 1 versus 0 in Group 2, but this difference was not significant. The combined nausea and vomiting score in the sufentanil group was higher than that in the lidocaine group $(P<0.05)$.

\section{Discussion}

Epidural sufentanil administered either as a bolus or by continuous infusion, has been shown to be an effective method of postoperative analgesia in abdominal, orthopaedic and thoracic surgical patients. ${ }^{4,9-11}$ The reported decrease in respiratory depression and increased duration of analgesia when sufentanil was administered with epi- nephrine, ${ }^{7}$ prompted the addition of $50, \mu g$ epinephrine to the bolus of $50 \mu \mathrm{g}$ sufentanil in Group I patients. The mean duration of analgesia of $288 \mathrm{~min}$ found in this study is considerably less than the $690 \mathrm{~min}$ reported in the above series, but conditions were different in that $75 \mu \mathrm{g}$ sufentanil was administered, and our patients had epidural lidocaine and were anaesthetised when the sufentanil was administered. The benefits of administration of opiates via the epidural route, as opposed to the conventional intravenous or intramuscular route, need to be balanced against the incidence of uncomfortable and, particularly, potentially dangerous side-effects such as cardiorespiratory depression. Other than a minor degree of somnolence in the sufentanil group, uncomfortable side-effects did not pose a serious problem in this study. In our anaesthetised patients, there were more clinically important haemodynamic effects than in at least one previous study, in which mean arterial pressure and heart rate decreases were not statistically significant. ${ }^{6}$

Many studies in awake patients describe some evidence of early postoperative respiratory depression following epidural sufentanil, but the results are inconsistent. Clinically unimportant respiratory depression was found following epidural administration of 30,50 or $75 \mu \mathrm{g}$ sufentanil in orthopaedic patients. ${ }^{9}$ However, a decreased slope of the $\mathrm{CO}_{2}$ response curve occurred 30 and $60 \mathrm{~min}$ after $0.75 \mu \mathrm{g} \cdot \mathrm{kg}^{-1}$ sufentanil was administered postoperatively to children following urological surgery. ${ }^{12}$ There were no decreases in minute volume. Following abdominal surgery in 30 patients the respiratory rate decreased by up to $30 \%$ for three hours, starting five minutes after the epidural bolus. ${ }^{6}$ Two patients had severe respiratory depression, with respiratory rates of four within ten minutes after the epidural opiate. The $\mathrm{PaCO}_{2}$ values were increased at one hour. Patients receiving sufentanil $10-50 \mu \mathrm{g}$ or fentanyl $100 \mu \mathrm{g}$ epidurally after Caesarean 
section under epidural lidocaine had minimal respiratory depression. ${ }^{1}$ Only four patients had a respiratory rate $<8 \cdot \min ^{-1}$, and only one out of the 40 who received sufentanil showed respiratory depression; none became apnoeic, and $\mathrm{PaCO}_{2}$ values were always $<6.5 \mathrm{kPa}$.

By contrast, in the very different population group represented by post-thoracotomy patients, two reports indicated severe respiratory depression after epidural sufentanil. Two patients in one study had severe respiratory depression and hypercarbia following a bolus of 50 $\mu \mathrm{g}$ sufentanil. However, $0.3 \mathrm{mg} \cdot \mathrm{kg}^{-1}$ intravenous morphine had been administered intraoperatively. ${ }^{13}$ In a further group of 22 patients randomised to receive 30,50 or $75 \mu \mathrm{g}$ sufentanil epidurally after thoracotomy, postoperative monitoring included continuous respiratory inductive plethysmography, to detect the number of apnoeic episodes. ${ }^{11}$ A respiratory rate $<10$ occurred in $2 / 6$ in the $50 \mu \mathrm{g}$ group and $7 / 7$ in the $75 \mu \mathrm{g}$ group. Apnoea occurred in $>50 \%$ of patients. The $\mathrm{PaCO}_{2}$ values were elevated in all groups and there were three life-threatening episodes in the $75 \mu \mathrm{g}$ group. Thoracotomy patients are, however, a select group whose preoperative respiratory patterns may predispose to respiratory failure.

It is well known that the control of ventilation is altered in the immediate postoperative period and that responses to hypercapnia are attenuated at low concentrations ( 0.1 MAC) of volatile agents. ${ }^{14,15}$ It was considered important, therefore, to study a group of anaesthetised, intubated, spontaneously breathing patients in whom the surgical stress response had been further reduced by epidural lidocaine. A continuous assessment could thus be made of respiratory indices following epidural opiate administration.

The respiratory depression in this study, despite an attempt to diminish systemic absorption of sufentanil by the addition of epinephrine. was considerably more marked than in most previous series of patients for abdominal surgery, in that the mean respiratory rate decreased from 20 per minute to $<10$ by $60 \mathrm{~min}$, the mean $\mathrm{PaCO}_{2}$ increased from 5.5 to $7 \mathrm{kPa}$ by $40 \mathrm{~min}$, and $5 / 20$ patients in the sufentanil group developed apnoea for $>20$ $\mathrm{sec}$, and their lungs were ventilated for the rest of the procedure. This probably reflects a considerable alteration in the $\mathrm{CO}_{2}$ response curve during general anaesthesia employing enflurane, and highlights the danger of allowing spontaneous ventilation following $50 \mu \mathrm{g}$ epidural sufentanil in the presence of anaesthetic agents. The typical pattern of opiate-induced respiratory depression in these anaesthetised patients, namely a decreased respiratory rate with increased tidal volume, is noteworthy in view of recent studies showing a poor correlation between the degree of hypoventilation and respiratory rate following epidural morphine. ${ }^{16,17}$
This study suggests severe early respiratory depression which peaks at $30-60 \mathrm{~min}$ following $50 \mu \mathrm{g}$ epidural sufentanil in anaesthetised patients for abdominal surgery. Estimation of serum sufentanil levels was not available for this study. However, the time course of the ventilatory depression suggests that systemic absorption of sufentanil was the most likely mechanism. The cardiorespiratory effects described here suggest that epidural sufentanil be employed with caution in the perioperative period in association with general anaesthesia (nitrous oxide and enflurane), in particular if patients are breathing spontaneously. Other general anaesthetic agents may well exhibit similar interactions with epidural sufentanil. The unpredictable nature of respiratory depression necessitates close monitoring in a high-care area for at least two hours after a bolus of $50 \mu \mathrm{g}$ sufentanil, even if epinephrine $50 \mu \mathrm{g}$ is included.

\section{References}

1 Madej TH, Strunin L. Comparison of epidural fentanyl with sufentanil. Anaesthesia 1987; 42: 1156-61.

2 Ready LB, Oden R, Chadwick HS, et al. Development of an anesthesiology-based postoperative pain management service. Anesthesiology 1988; 68: 100-6.

3 Etches RC, Sandler AN, Daley $M D$. Respiratory depression and spinal opioids. Can J Anaesth 1989; 36: 165-85.

4 Verborgh C, Van der Auwera D, Van Droogenbroek E, Camu F. Epidural sufentanil for postsurgical pain relief. Eur J Anaesthesiol 1986; 3: 313-20.

5 Cohen SE, Tan S, White PF. Sufentanil analgesia following Caesarean section: epidural versus intravenous administration. Anesthesiology 1988; 68: 129-34.

6 Van der Auwera D, Verborgh C, Camu F. Analgesic and cardiorespiratory effects of epidural sufentanil and morphine in humans. Anesth Analg 1987; 66: 999-1003.

7 Verborgh C, Van der Auwera D, Noorduin H, Camu $F$. Epidural sufentanil for postoperative pain relief and effects of adrenaline. Eur J Anaesthesiol 1988; 5: 183-91.

8 Bromage $P R$. A comparison of the hydrochloride and carbon dioxide salts of lignocaine and prilocaine in epidural analgesia. Acta Anaesthesiol Scand (Suppl) 1965b; 16: 55-69.

9 Donadoni $R$, Rolly $G$, Noorduin H, Van den Bussche $G$. Epidural sufentanil for postoperative pain relief. Anaesthesia 1985; 40: 634-8.

10 Dyer RA, Anderson BJ, Michell WL, Hall JM. Post operative pain control with a continuous infusion of epidural sufentanil in the Intensive Care Unit: a comparison with epidural morphine. Anesth Analg 1990; 71: 130-6.

11 Whiting WC, Sandler AN, Lau LC, et al. Analgesic and respiratory effects of epidural sufentanil in patients following thoracotomy. Anesthesiology 1988; 69: 36-43. 
12 Benlabed M, Ecoffey C, Levron J-C, Flaisler B, Gross JB. Analgesia and ventilatory response to $\mathrm{CO}_{2}$ following epidural sufentanil in children. Anesthesiology 1987; 67: 948-51.

13 Vercauteren $M$, Boeckx $E$, Noorduin $H$. Respiratory arrest after sufentanil. Anaesthesia 1988; 43: 69-70.

14 Knill RL, Gelb AW. Ventilatory responses to hypoxia and hypercapnia during halothane sedation and anaesthesia in man. Anesthesiology 1978; 49: 244-51.

15 Knill RL, Manninen PH, Clement JL. Ventilation and chemoreflexes during enflurane sedation and anaesthesia. Can Anaesth Soc J 1979; 26: 353-60.

16 Rawal N, Wattwil M. Respiratory depression after epidural morphine - an experimental and clinical study. Anesth Analg 1984; 63: 8-14.

17 Madsen JV, Rybro L, Schurizek BA et al. Respiratory depression following postoperative analgesia with epidural morphine. Acta Anaesthesiol Scand 1986; 30: 417-20. 